\title{
Acute haemodynamic and metabolic effects of felodipine in congestive heart failure
}

\author{
A D TIMMIS, S CAMPBELL, M J MONAGHAN, L WALKER, D E JEWITT \\ From the Department of Cardiology, King's College Hospital, London
}

SUMmaRY Felodipine is a new calcium antagonist with a high degree of vascular selectivity. To examine its potential value as an afterload reducing agent in congestive heart failure 11 patients were studied. Substantial increments in cardiac index were associated with a fall in systemic vascular resistance. Left ventricular end diastolic pressure was also significantly reduced. Although left ventricular maximum $\mathrm{dP} / \mathrm{dt}$ remained unchanged, maximum $\mathrm{dP} / \mathrm{dt} / \mathrm{P}$ increased. Left ventricular unloading was reflected by a reduction in cavity dimensions and a shift in the relation between end systolic pressure and dimension downwards and to the left. The myocardial oxygen supply to demand ratio was also improved: coronary sinus flow increased significantly despite a decline in myocardial oxygen consumption. These beneficial haemodynamic and metabolic effects suggest that felodipine may extend the clinical application of calcium antagonists to include the treatment of congestive heart failure.

Calcium antagonists such as nifedipine and verapamil reduce the inward flux of calcium ions across cell membranes by their inhibitory action on the calcium slow channel. ${ }^{1}$ These drugs are particularly active in the myocardium and vascular smooth muscle, in which the reduction in intracellular calcium ions impairs excitation-contraction coupling thereby inducing negative inotropism and vasodilatation. ${ }^{2}$ The combination of these separate cardiovascular influences probably underlies the efficacy of calcium antagonists in the treatment of angina and hypertension. ${ }^{3-5}$

The systemic vasodilator effects of calcium antagonists indicate a potential role for this type of treatment in patients with left ventricular failure. A number of acute clinical studies have shown a useful improvement in left ventricular function which-in contrast to the in vitro findings-usually occurs without deterioration in derived indices of contractility. ${ }^{6-9}$ Other investigators, ${ }^{10}$ however, have provided clear evidence of a negative inotropic response to calcium antagonists in patients with severe heart failure, which probably accounts for earlier reports of circulatory collapse and pulmonary oedema during treatment with these compounds. ${ }^{11-14}$ For this reason

Requests for reprints to Dr D E Jewitt, Department of Cardiology, King's College Hospital, Denmark Hill, London SE5 9RS.

Accepted for publication 29 November 1983 calcium antagonists are not at present widely used in congestive heart failure.

The recent introduction of felodipine, however-a nifedipine analogue with pronounced vascular selectivity-promises to extend the clinical application of this class of agents. Experimental work has shown that felodipine is a potent vasodilator with negligible effects on the myocardium. ${ }^{15} 16$ These properties distinguish felodipine from all the currently available calcium antagonists and indicate that the drug might be used safely as an afterload reducing agent in patients with congestive heart failure. The present study was designed to examine this issue. Particular attention was directed towards evaluating the effects of felodipine on left ventricular systolic function, systemic and coronary haemodynamics, and myocardial substrate metabolism.

\section{Patients and methods}

\section{PATIENT SELECTION}

Eleven men aged from 38 to 66 (mean 57.4) years were studied. All were selected on the basis of severe congestive heart failure (New York Heart Association functional class III and IV), which had responded inadequately to conventional treatment. None of the patients had been treated with calcium antagonists. Cardiac catheterisation performed within six months of the study had confirmed severely impaired left ven- 
tricular function with a mean $( \pm S E M)$ angiographic ejection fraction of only $20 \pm 3 \%$. Ten of the group had triple vessel coronary artery disease and one a congestive cardiomyopathy of unknown aetiology. All the patients were in stable sinus rhythm. Exclusion criteria included acute myocardial infarction during the previous six months, stenotic valvular heart disease, and diabetes requiring treatment with insulin or oral hypoglycaemic agents. All patients had given written informed consent before inclusion in the study.

\section{INSTRUMENTATION}

The patients were studied in the supine position after an overnight fast and premedication with diazepam 5 to $10 \mathrm{mg}$ orally. Heparin $1000 \mathrm{IU} / \mathrm{h}$ was given by continuous intravenous infusion for 12 hours before and during each study. All catheter procedures were performed under fluoroscopic control. A balloon tipped triple lumen thermodilution catheter (Edwards Laboratories) was placed in the pulmonary artery for right sided pressure measurements and computation of cardiac ouput. The mean of at least four cardiac output readings was taken for each estimation. The coronary sinus was cannulated with a dual thermistor catheter (Wilton Webster) according to the techniques described by Ganz et al. ${ }^{17}$ This permitted coronary sinus blood sampling and the measurement of coronary sinus flow by continuous thermodilution. Arterial pressure was monitored, and blood samples obtained, through the sidearm of a short sheath positioned in the femoral artery. A micromanometer tip catheter (Millar Instruments) was introduced through the femoral arterial sheath and positioned in the left ventricle for high fidelity pressure recordings. All pressures were measured with reference to the mid-chest and were recorded with an electrocardiogram on a Mingograph 82 recorder (Siemens).

In five patients, $M$ mode echocardiograms (Hewlett Packard, phased array sector scanner) of the left ventricular cavity were obtained at a level just below the free margins of the mitral valve leaflets where the septum and posterior wall were clearly visible. These images were recorded simultaneously with the left ventricular pressure signal at a paper speed of 100 $\mathrm{mm} / \mathrm{s}$. During the simultaneous echocardiograms and pressure recordings- which rarely took longer than $30 \mathrm{~s}$ to complete-the atrium was paced at a fixed preselected rate ( 15 beats/min in excess of the control heart rate).

\section{PROTOCOL}

All vasodilator treatment was discontinued four days before the study. Diuretics and non-essential medications were withheld on the morning of the study. After placement of the catheters the patients were permitted to rest for 15 minutes, and two sets of control haemodynamic measurements were then obtained 20 minutes apart. At the same times blood samples were withdrawn from the coronary sinus and the femoral artery for later biochemical analysis. Felodipine $5 \mathrm{mg}$ was given orally, and 20 minutes later haemodynamic measurements and blood sampling were repeated. Three patients in whom the systolic blood pressure fell below $90 \mathrm{~mm} \mathrm{Hg}$ (a preselected endpoint) received no further felodipine. The remainder of the group were given two additional doses of felodipine $5 \mathrm{mg}$. Twenty minutes after each dose increment a further set of haemodynamic measurements were obtained, and blood sampling was repeated. The simultaneous left ventricular echocardiogram and pressure recordings were obtained at the same time intervals but always after the other haemodynamic variables had been measured and the blood samples had been taken.

\section{DATA ANALYSIS}

Measurements of stroke volume and vascular resistance (expressed in arbitrary units) were derived by standard formulae. Cardiac output and stroke volume were normalised for body surface area. The rate of rise of left ventricular pressure $(\mathrm{dP} / \mathrm{dt})$ and the quotient of $\mathrm{dP} / \mathrm{dt}$ and instantaneous pressure $(\mathrm{P})$ were derived by simultaneous analogue processing of the left ventricular pressure signal. The simultaneous records of left ventricular pressure and septal and posterior wall endocardial echoes were digitised between two consecutive $R$ waves on the electrocardiogram with a high resolution $(0.1 \mathrm{~mm})$ digitising tablet (Summagraphics) interfaced with a microcomputer system (Commodore).

Arterial and coronary sinus blood samples were assayed for plasma free fatty acids ${ }^{18}$ and whole blood lactate ${ }^{19}$ and glucose.20 Whole blood oxygen and haemoglobin concentrations were measured using a Radiometer OSM2 Hemoximeter; oxygen content was derived by standard formulae. Arteriocoronary sinus concentration differences in whole blood were calculated for each substrate, and the myocardial extraction ratios were derived by dividing the arteriocoronary sinus difference by the arterial level expressed as a percentage. Myocardial uptake for each substrate was calculated as the product of arteriocoronary sinus concentration difference in whole blood and coronary sinus blood flow.

\section{STATISTICAL ANALYSIS}

Two way analysis of variance was used to test the significance of the overall changes in individual haemodynamic and metabolic variables across time. Those variables which changed significantly $(p<0.05)$ were then subjected to a modified $t$ test-by the Bon- 


\section{Felodipine in heart failure}

feronni method-to identify the source of the differences. ${ }^{21}$

\section{Results}

\section{HAEMODYNAMIC RESPONSES}

The haemodynamic responses to felodipine are summarised in Table 1. Individual patient data are given in Fig. 1.

The severe left ventricular impairment in these patients was confirmed by the control haemodynamic data, which showed a considerable increase in the left ventricular filling pressure and reductions in both the cardiac output and the isovolumic indices of contractile state. Left ventricular impairment is also illustrated by the pronounced rightward shift of the control pressure/dimension diagrams (Fig. 2).

After administration of felodipine cardiac index and stroke volume index substantially increased in all patients and was associated with a quantitatively similar reduction in systemic vascular resistance. In the eight patients who received a total cumulative dose of $15 \mathrm{mg}$ these changes were largely dose related during the first two increments, but thereafter responses usually reached a plateau (Fig. 1). Although right atrial pressure did not change significantly, the left ventricular filling pressures-measured by left ventricular end diastolic pressure and pulmonary capillary wedge pressure-fell considerably (Fig. 1). Small increments in heart rate occurred in seven patients, but these never exceeded 10 beats/min and the overall changes were not significant. Blood pressure, however, showed an appreciable reduction, which was of
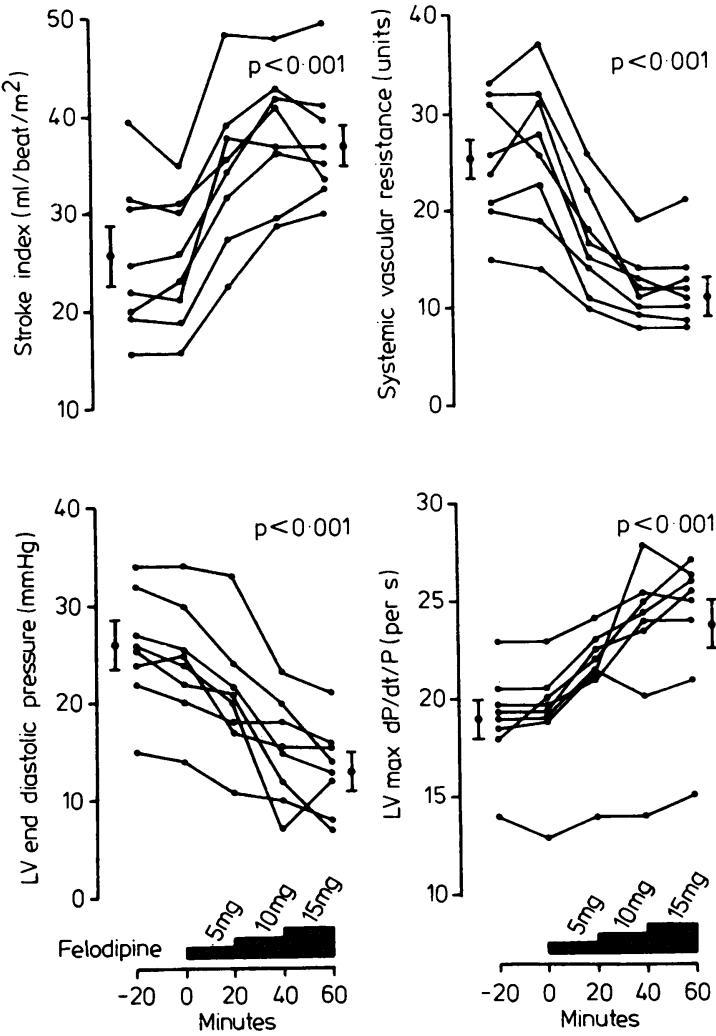

Fig. 1 Effects of felodipine on stroke index and haemodynamic measures of preload, afterload, and contractility in eight patients. Points and bars are means $\pm S E M$ at baseline and after the maximum dose increment. $L V$, left ventricular.

Table 1 Haemodynamic responses (mean values $\pm S E M$ ) to felodipine in eight patients with congestive heart failure. Figures in parentheses are data or 11 patients who received only $5 \mathrm{mg}$ felodipine

\begin{tabular}{|c|c|c|c|c|c|c|}
\hline & \multirow[t]{2}{*}{ Control values (1) } & \multirow[t]{2}{*}{ Control values (2) } & \multicolumn{3}{|l|}{ Cumulative dose } & \multirow[t]{2}{*}{ p Value } \\
\hline & & & $5 \mathrm{mg}$ & $10 m g(n=8)$ & $15 m g(n=8)$ & \\
\hline $\begin{array}{l}\text { Heart rate (beats/min) } \\
\text { Cardiac index }\left(1 / \mathrm{min} / \mathrm{m}^{2}\right) \\
\text { Stroke volume index }\left(\mathrm{m} / \mathrm{beat} / \mathrm{m}^{2}\right) \\
\text { Systolic blood pressure (mm } \mathbf{H g}) \\
\text { Disstolic blood pressure (mm Hg) } \\
\text { Systemic vascular resistance (units) } \\
\text { Mean right atrial pressure (mm Hg) }\end{array}$ & $\begin{array}{l}88 \pm 8(86 \pm 6) \\
2 \cdot 1 \pm 0 \cdot 1(2 \cdot 1 \pm 0 \cdot 1) \\
24 \pm 2(24 \pm 2) \\
134 \pm 6(125 \pm 7) \\
81 \pm 3(74 \pm 4) \\
26 \pm 2(24 \pm 2) \\
9 \pm 2(8 \pm 2)\end{array}$ & $\begin{array}{l}89 \pm 9(87 \pm 6) \\
2 \cdot 1 \pm 0 \cdot 1(2 \cdot 1 \pm 0 \cdot 1) \\
24 \pm 2(24 \pm 2) \\
139 \pm 7(128 \pm 8) \\
81 \pm 5(75 \pm 5) \\
26 \pm 3(24 \pm 2) \\
9 \pm 2(8 \pm 2)\end{array}$ & $\begin{array}{l}91 \pm 8(90 \pm 6) \\
3 \cdot 0 \pm 0 \cdot 1^{\star \star \star}\left(2 \cdot 9 \pm 0 \cdot 1^{\star \star \star}\right) \\
33 \pm 2^{\star \star \star}\left(32 \pm 2^{\star \star \star}\right) \\
123 \pm 7^{\star \star}\left(112 \pm 8^{\star \star \star}\right) \\
70 \pm 4^{\star}\left(65 \pm 4^{\star \star}\right) \\
16 \pm 2^{\star \star \star}\left(16 \pm 1^{\star \star \star}\right) \\
9 \pm 3(8 \pm 2)\end{array}$ & $\begin{array}{l}92 \pm 6 \\
3 \cdot 5 \pm 0.2^{\star \star \star} \\
38 \pm 2^{\star \star \star} \\
108 \pm 5^{\star \star} \\
60 \pm 2^{\star \star} \\
12 \pm 1^{\star \star \star} \\
8 \pm 2\end{array}$ & $\begin{array}{l}90 \pm 6 \\
3 \cdot 3 \pm 0 \cdot 2^{\star \star \star} \\
37 \pm 2^{\star \star \star} \\
100 \pm 4^{\star \star \star} \\
57 \pm 2^{\star \star \star} \\
12 \pm 2^{\star \star \star} \\
8 \pm 3\end{array}$ & $\begin{array}{l}\text { NS } \\
<0001 \\
<0001 \\
<0001 \\
<0.001 \\
<0001 \\
\text { NS }\end{array}$ \\
\hline $\begin{array}{l}\text { Mean pulmonary artery pressure } \\
\text { (mm Hg) }\end{array}$ & $38 \pm 5(34 \pm 4)$ & $37 \pm 5(34 \pm 4)$ & $32 \pm 4^{\star}\left(30 \pm 2^{\star}\right)$ & $29 \pm 4^{\star}$ & $27 \pm 3^{\star}$ & $<0.001$ \\
\hline $\begin{array}{l}\text { Mean pulmonary capillary wedge } \\
\text { pressure (mm Hg) } \\
\text { Pulmonary vascular resistance (units) } \\
\text { Left ventricular end diastolic pressure }\end{array}$ & $\begin{array}{l}26 \pm 4(23 \pm 4) \\
3.1 \pm 0.6(2 \cdot 8 \pm 0.5)\end{array}$ & $\begin{array}{l}26 \pm 4(22 \pm 3) \\
3.0 \pm 0.5(2 \cdot 9 \pm 0.3)\end{array}$ & $\begin{array}{l}21 \pm 3^{\star}\left(18 \pm 3^{\star \star}\right) \\
1 \cdot 9 \pm 0 \cdot 3^{\star}(2 \cdot 1 \pm 0 \cdot 2)\end{array}$ & $\begin{array}{l}17 \pm 3^{\star} \\
1 \cdot 9 \pm 0.3\end{array}$ & $\begin{array}{l}15 \pm 2^{\star \star} \\
1 \cdot 9 \pm 0.3^{\star}\end{array}$ & $\begin{array}{l}<0.001 \\
<0-001\end{array}$ \\
\hline $\begin{array}{l}\text { (mm Hg) } \\
\text { Left ventricular max dP/dt (mm Hg/s) } \\
\text { Left ventricular } \mathrm{max} \mathrm{dP} / \mathrm{dt} / \mathrm{P} \text { (per s) } \\
\text { Coronary sinus flow (m//min) } \\
\text { Coronary resistance (units) }\end{array}$ & $\begin{array}{l}26 \pm 2(22 \pm 2) \\
1199 \pm 113(1073 \pm 105) \\
19 \pm 1(19 \pm 1) \\
141 \pm 11(137 \pm 15) \\
0.66 \pm 0.05(0.64 \pm 0.04)\end{array}$ & $\begin{array}{l}24 \pm 3(21 \pm 2) \\
1193 \pm 114(1076 \pm 103) \\
19 \pm 1(19 \pm 1) \\
149 \pm 15(148 \pm 13) \\
0-64 \pm 0.06(0-61 \pm 0-05)\end{array}$ & $\begin{array}{l}21 \pm 3^{\star \star}\left(18 \pm 2^{\star}\right) \\
1169 \pm 128(1044 \pm 113) \\
21 \pm 1^{\star}\left(21 \pm 1^{\star \star}\right) \\
158 \pm 15(158 \pm 14) \\
0.57 \pm 0.08\left(0.53 \pm 0.07^{\star}\right)\end{array}$ & $\begin{array}{l}15 \pm 2 \star \\
1136 \pm 95 \\
24 \pm 2 \star \\
152 \pm 15 \\
0.49 \pm 0.06 \star\end{array}$ & $\begin{array}{l}13 \pm 2 \star \star \\
1079 \pm 93 \\
24 \pm 1^{\star} \\
176 \pm 15^{\star} \\
0-38 \pm 0.04 \star \star\end{array}$ & $\begin{array}{l}<0-001 \\
\text { NS } \\
<0.001 \\
<0.05 \\
<0.001\end{array}$ \\
\hline
\end{tabular}

*Overall significance of changes by analysis of variance (ANOVA).

Significance of individual changes with respect to the first set of control readings: ${ }^{\star} p<0.05,{ }^{\star \star} p<0.01,{ }^{\star \star} p<0.001$. 

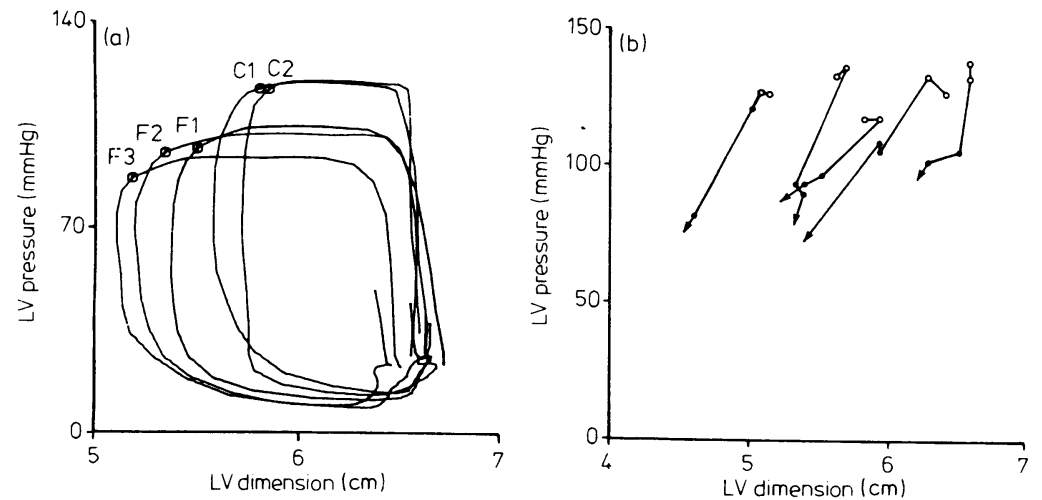

Fig. 2 (a) Effect of felodipine on the left ventricular pressure/dimension relation in a single patient. Two control diagrams (CI and C2) are shown and also the diagrams after each of the three dose increments of felodipine (FI to F3). $\bigcirc-\bigcirc$ indicate the pressure/dimension relation at end systole. (b) Effect of felodipine on the end systolic pressure/dimension relation in five patients. For each case two control points are shown $(O)$ and the changes in response to incremental doses of felodipine ( $\bigcirc$ and arrow).

similar degree for both the systolic and diastolic measurements. No important changes in the maximum left ventricular $\mathrm{dP} / \mathrm{dt}$ were observed, but maximum $\mathrm{dP} / \mathrm{dt} / \mathrm{P}$ increased in every patient (Fig. 1).

Felodipine significantly lowered the pulmonary and coronary vascular resistances. The alteration in coronary resistance occurred during an increase in coronary sinus flow, which was most pronounced at the highest dose increment.

The reduction in left ventricular pressures in response to felodipine was associated with a directionally similar change in the systolic and diastolic cavity dimensions. A pronounced downward and leftward shift of the end systolic pressure to dimension relation was observed (Fig. 2).

\section{METABOLIC RESPONSES}

Arterial concentrations of glucose and lactate did not change appreciably during the study (Table 2). The small increase in arterial free fatty acid concentration and the small reduction in arterial oxygen saturation (Fig. 3) were both, however, statistically significant. The myocardial extraction of all the major organic substrates decreased substantially, but despite this the

Table 2 Metabolic responses (mean values $\pm S E M$ ) to felodipine in eight patients with congestive heart failure. Figures in parentheses are dato 11 patients who received only $5 \mathrm{mg}$ felodipine

\begin{tabular}{|c|c|c|c|c|c|c|}
\hline & \multirow[t]{2}{*}{ Control values (1) } & \multirow[t]{2}{*}{ Control values (2) } & \multicolumn{3}{|l|}{ Cumulative dose } & \multirow[t]{2}{*}{$p$ Value } \\
\hline & & & $5 \mathrm{mg}$ & $10 m g(n=8)$ & $15 m g(n=8)$ & \\
\hline $\begin{array}{l}\text { Free fatty acids } \\
\text { Arterial concentration }(\mathrm{mmol} / \mathrm{l}) \\
\text { Myocardial extraction }(\%) \\
\text { Myocardial uptake }(\mu \mathrm{mol} / \mathrm{min})\end{array}$ & $\begin{array}{l}0.98 \pm 0.08(1.05 \pm 0.09) \\
34 \pm 3(34 \pm 4) \\
22 \cdot 3 \pm 3 \cdot 3(20 \cdot 7 \pm 3 \cdot 0)\end{array}$ & $\begin{array}{l}1 \cdot 21 \pm 0 \cdot 18(0 \cdot 99 \pm 0 \cdot 07) \\
32 \pm 4(33 \pm 4) \\
22 \cdot 2 \pm 4 \cdot 1(20 \cdot 9 \pm 3 \cdot 0)\end{array}$ & $\begin{array}{l}1.00 \pm 0.07(0.92 \pm 0.07) \\
27 \pm 6(28 \pm 4) \\
18 \cdot 8 \pm 5.9(16.4 \pm 4 \cdot 4)\end{array}$ & $\begin{array}{l}1 \cdot 15 \pm 0 \cdot 08^{\star} \\
22 \pm 4^{\star} \\
17 \cdot 4 \pm 5 \cdot 3\end{array}$ & $\begin{array}{l}1 \cdot 10 \pm 0 \cdot 08 \\
17 \pm 4 \star \star \\
14 \cdot 8 \pm 4 \cdot 4\end{array}$ & $\begin{array}{l}<0.05 \\
<0 \cdot 01 \\
\text { NS }\end{array}$ \\
\hline $\begin{array}{l}\text { Glucose } \\
\text { Arterial concentration (mmol/l) } \\
\text { Myocardial extraction }(\%) \\
\text { Myocardial uptake }(\mu \mathrm{mol} / \mathrm{min})\end{array}$ & $\begin{array}{l}4 \cdot 6 \pm 0 \cdot 3(4 \cdot 7 \pm 0 \cdot 2) \\
8 \pm 3(7 \pm 2) \\
45 \cdot 0 \pm 16 \cdot 4(40 \cdot 8 \pm 11 \cdot 5)\end{array}$ & $\begin{array}{l}4 \cdot 6 \pm 0 \cdot 2(4 \cdot 7 \pm 0 \cdot 2) \\
8 \pm 4(7 \pm 2) \\
41 \cdot 9 \pm 17 \cdot 0(38 \cdot 9 \pm 11 \cdot 7)\end{array}$ & $\begin{array}{l}5 \cdot 0 \pm 0 \cdot 4(5 \cdot 0 \pm 0 \cdot 3) \\
7 \pm 3(4 \pm 2) \\
33 \cdot 5 \pm 12 \cdot 0(17 \cdot 3 \pm 12 \cdot 9)\end{array}$ & $\begin{array}{l}4 \cdot 9 \pm 0 \cdot 4 \\
5 \pm 4 \\
45 \cdot 2 \pm 17 \cdot 2\end{array}$ & $\begin{array}{l}5 \cdot 1 \pm 0 \cdot 4 \\
4 \pm 2^{\star \star} \\
37 \cdot 4 \pm 18 \cdot 7\end{array}$ & $\begin{array}{l}\text { NS } \\
<0 \cdot 01 \\
\text { NS }\end{array}$ \\
\hline $\begin{array}{l}\text { Lactate } \\
\text { Arterial concentration }(\mathrm{mmol} / \mathrm{l}) \\
\text { Myocardial extraction }(\%) \\
\text { Myocardial uptake }(\mu \mathrm{mol} / \mathrm{min})\end{array}$ & $\begin{array}{l}11 \cdot 2 \pm 1 \cdot 5(10 \cdot 7 \pm 1 \cdot 2) \\
30 \pm 6(30 \pm 5) \\
4 \cdot 6 \pm 1 \cdot 2(4 \cdot 5 \pm 1 \cdot 0)\end{array}$ & $\begin{array}{l}10 \cdot 9 \pm 1 \cdot 4(10 \cdot 6 \pm 1 \cdot 1) \\
26 \pm 5(28 \pm 5) \\
4 \cdot 1 \pm 1 \cdot 0(4 \cdot 4 \pm 0 \cdot 9)\end{array}$ & $\begin{array}{l}10 \cdot 1 \pm 1 \cdot 2(9 \cdot 8 \pm 0 \cdot 9) \\
21 \pm 6(22 \pm 5) \\
3 \cdot 1 \pm 1 \cdot 1(3 \cdot 2 \pm 0 \cdot 9)\end{array}$ & $\begin{array}{l}10 \cdot 1 \pm 1 \cdot 3 \\
20 \pm 5^{\star} \\
3 \cdot 0 \pm 0 \cdot 8\end{array}$ & $\begin{array}{l}10 \cdot 6 \pm 1 \cdot 3 \\
14 \pm 4^{\star \star \star} \\
2 \cdot 2 \pm 0.5\end{array}$ & $\begin{array}{l}\text { NS } \\
<0.001 \\
\text { NS }\end{array}$ \\
\hline $\begin{array}{l}\text { Oxygen } \\
\text { Aterial saturation }(\%) \\
\text { Myocardial extraction }(\%) \\
\text { Myocardial uptake }(\mu \mathrm{mol} / \mathrm{min})\end{array}$ & $\begin{array}{l}90 \cdot 6 \pm 1 \cdot 0(92 \cdot 0 \pm 1 \cdot 1) \\
78 \pm 3(76 \pm 2) \\
17 \cdot 8 \pm 1 \cdot 6(16 \cdot 9 \pm 1 \cdot 3)\end{array}$ & $\begin{array}{l}90 \cdot 8 \pm 0.9(92 \cdot 3 \pm 1 \cdot 0) \\
78 \pm 2(76 \pm 2) \\
18 \cdot 8 \pm 2 \cdot 2(17.9 \pm 1 \cdot 7)\end{array}$ & $\begin{array}{l}87 \cdot 9 \pm 1 \cdot 3\left(89 \cdot 8 \pm 1 \cdot 4^{\star}\right) \\
66 \pm 3^{\star \star}\left(65 \pm 3^{\star}\right) \\
15 \cdot 9 \pm 2 \cdot 1(15 \cdot 6 \pm 1 \cdot 6)\end{array}$ & $\begin{array}{l}86 \cdot 7 \pm 0 \cdot 9 \star \star \\
59 \pm 4 \star \star \star \\
14 \cdot 0 \pm 1 \cdot 7 \star\end{array}$ & $\begin{array}{l}86 \cdot 3 \pm 0 \cdot 9 \star \star \\
56 \pm 4 \star \star \star \\
14 \cdot 3 \pm 1 \cdot 2^{\star}\end{array}$ & $\begin{array}{l}<0.001 \\
<0.001 \\
<0.05\end{array}$ \\
\hline
\end{tabular}

*Overall significance of the changes by analysis of variance (ANOVA).

Significance of individual changes with respect to the first set of control readings: ${ }^{\star} p<0.05,{ }^{\star \star} p<0.01,{ }^{\star \star \star} p<0.001$. 

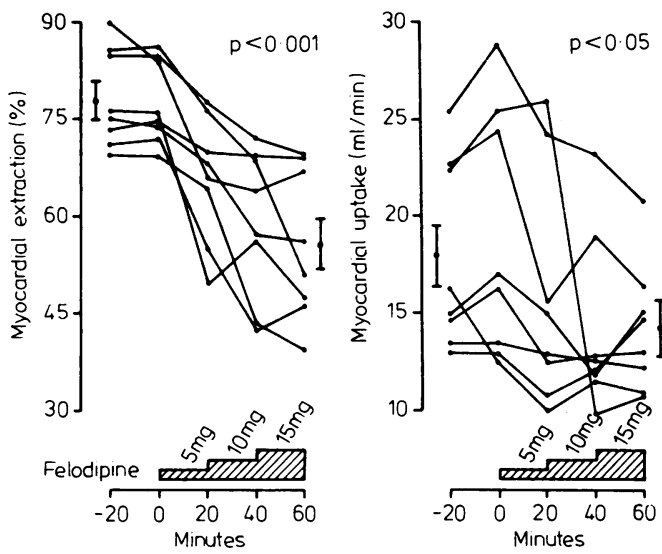

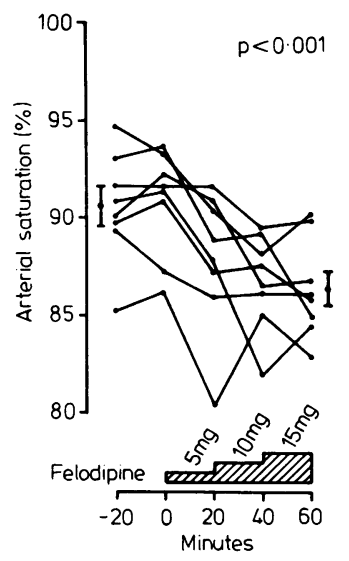

Fig. 3 Effects of felodipine on oxygen metabolism in eight patients. Points and bars are means $\pm S E M$ at baseline and after the maximum dose increment. utilisation of these substrates was unaffected. Myocardial oxygen extraction was also reduced; importantly, however, this was associated with a significant reduction in myocardial oxygen consumption (Fig. 3).

\section{DRUG RELATED SIDE EFFECTS}

Felodipine was generally well tolerated, and drug related side effects were reported by only two patients, both of whom experienced facial flushing which in one case was associated with headache. An asymptomatic decline in systolic blood pressure below $90 \mathrm{~mm} \mathrm{Hg}$ occurred after felodipine $5 \mathrm{mg}$ in three patients, all of whom had resting values of $\leqslant 104 \mathrm{~mm}$ $\mathrm{Hg}$. No further drug was given, and recovery occurred within one hour in each case.

\section{Discussion}

These data show that the acute administration of oral felodipine to patients with severe congestive heart failure produces a substantial improvement in systemic and coronary circulatory dynamics without impairing the contractile function of the left ventricle. Moreover, the beneficial haemodynamic effects of this agent are associated with a simultaneous reduction in myocardial oxygen consumption.

The patients selected for inclusion in this study all had critical left ventricular dysfunction manifested by variable reductions in cardiac output and increases in the left sided filling pressures. The improvement in these haemodynamic indices that occurred during felodipine treatment is consistent with drug mediated vasodilatation. Thus felodipine, by relaxing arteriolar smooth muscle, lowered the peripheral vascular resistance and blood pressure. The consequent reduction in afterload led to a considerable increase in cardiac output and stroke volume. This increase in forward flow occurred despite a pronounced reduction in left ventricular filling pressure. Peripheral arteriolar dilatation will itself have tended to reduce preload by favourably influencing diastolic (as well as systolic) cavity dimensions. ${ }^{22}$ Associated venous pooling, however, cannot be excluded even though calcium antagonists usually have relatively little effect on the capacitance vessels. ${ }^{1}$

The changes in the relation between end systolic pressure and dimension that occurred in response to felodipine indicate that the reduction in left ventricular pressure was associated with a simultaneous reduction in cavity dimension. In the normal heart the end systolic pressure/dimension relation is as sensitive to changes in inotropic state as the more widely used end systolic pressure/volume relation, ${ }^{23}$ reflecting the almost linear correlation that exists between ventricular dimension and volume. ${ }^{24}$ But in patients with heart failure and coronary artery disease the distorted left ventricular geometry is likely to render the end systolic pressure/dimension relation a relatively less sensitive index of inotropic state, and our data, therefore, require cautious interpretation. ${ }^{25}$ The shift in this relation downwards and to the left, however, occurred in every patient studied. This is consistent with afterload reduction being the dominant mechanism for felodipine's beneficial haemodynamic effects and strongly suggests that significant negative inotropism did not occur. ${ }^{25}$

The effects of felodipine on isovolumic indices of left ventricular function indicate that contractile state did not deteriorate and provide further evidence that this drug is not appreciably negatively inotropic. Indeed, although left ventricular maximum $\mathrm{dP} / \mathrm{dt}$ did not change (probably because of the pronounced reduction in loading) maximum $\mathrm{dP} / \mathrm{dt} / \mathrm{P}$ showed a small but consistent increase indicating an overall improvement in inotropic state. ${ }^{26} 27$ The mechanisms 
responsible for this beneficial response are not clear but are unlikely to relate to a direct effect of the drug on the myocardium. Other investigators who have reported similar findings during vasodilator treatment have invoked reflex sympathetic activity or reduction in regional ischaemia as possible explanations. ${ }^{28}$ Neither seems adequate in the context of the present study since heart rate (and by inference reflex sympathetic activity) did not increase significantly and, in addition, the single patient with a non-ischaemic cardiomyopathy showed a rise in maximum $\mathrm{dP} / \mathrm{dt} / \mathrm{P}$, which was similar in magnitude to that in the remainder of the group. Regardless of the mechanism involved, however, the small improvement in the contractile function of the left ventricle during felodipine treatment indicates that the drug may be used safely in patients with congestive heart failure.

The reduction in left ventricular wall tension and cavity size that occurred in response to felodipine led to a significant decline in myocardial oxygen consumption. 29 But despite the reduced myocardial oxygen requirement and the simultaneous lowering of coronary perfusion pressure, a modest increase in coronary blood flow was seen. This must reflect direct drug induced dilatation of the coronary system. ${ }^{30}$ The beneficial effects of felodipine on myocardial oxygen supply and demand more than offset the potentially deleterious effect of the small reduction in arterial oxygen saturation that occurred during treatment. A similar phenomenon has been reported with other vasodilators-particularly those which, like felodipine, reduce pulmonary vascular resistance. ${ }^{31}$ Alterations in ventilation/perfusion relations in the lungs-due to redistribution of flow to poorly ventilated alveoli-is the likely explanation for this adverse effect. In practical terms, however, the reduction in arterial oxygen saturation was too small to be of clinical significance. The overall improvement in the myocardial oxygen supply to demand ratio is likely, therefore, to have been considerable, indicating a useful role for felodipine when heart failure is a complication of coronary artery disease.

In other respects felodipine had no important effects on the metabolic function of the myocardium. The small rise in the arterial concentration of free fatty acids is a predictable consequence of starvation, which had always started at least 10 hours previously and which continued thoughout the time it took to complete the study - about three hours. Although the myocardial extraction of all the organic substrates fell significantly, this simply reflects the increase in coronary flow since the coronary sinus concentrations of these compounds increased without significant change in their uptake by the heart.

The selective vasodilator properties of felodipine are confirmed in the present study. Although the patients all had severe left ventricular dysfunction, the drug was well tolerated and showed no tendency to impair further the inotropic state of the myocardium. These findings appear to bear out the theoretical advantages that felodipine has over other calcium antagonists in patients of this type. The beneficial haemodynamic and metabolic effects of felodipine that occurred in this study indicate a role for this agent in the management of congestive heart failure. A proper evaluation of this role, however, will require further studies in ambulant patients: if these can show sustained benefit during chronic treatment felodipine is likely to be useful in the long term management of this condition.

\section{References}

1 Braunwald E. Mechanism of action of calcium-channelblocking agents. $N$ Engl f Med 1982; 307: 1618-27.

2 Fleckenstein A. Specific pharmacology of calcium in myocardium, cardiac pacemakers and vascular smooth muscle. Annu Rev Pharmacol Toxicol 1977; 17: 149-66.

3 Moskowitz RM, Piccini PA, Nacarelli GV, Zelis R. Nifedipine therapy for stable angina pectoris: preliminary results of effects on angina frequency and treadmill exercise response. Am $\mathcal{F}$ Cardiol 1979; 44: 811-6.

4 Stone PH, Turi ZG, Muller JE. Efficacy of nifedipine therapy for refractory angina pectoris. Am Heart $\mathcal{F}$ 1982; 104: 672-81.

5 Stone PH, Antman EM, Muller JE, Braunwald E. Calcium channel blocking agents in the treatment of cardiovascular disorder. II. Hemodynamic effects and clinical applications. Ann Intern Med 1980; 93: 886-904.

6 Polese A, Fiorentini C, Olivari MT, Guazzi MD. Clinical use of a calcium antagonistic agent (nifedipine) in acute pulmonary edema. Am $\mathcal{F}$ Med 1979; 66: 825-30.

7 Klugmann S, Salvi A, Camerini F. Haemodynamic effects of nifedipine in heart failure. Br Heart $\mathcal{F} 1980$; 43: $440-6$.

8 Lorell BH, Turi Z, Grossman W. Modification of left ventricular response to pacing tachycardia by nifedipine in patients with coronary artery disease. $A m \mathcal{F}$ Med 1981; 71: $667-75$.

9 Ludbrook PA, Tiefenbrunn AJ, Reed FR, Sobel BE. Acute hemodynamic responses to sublingual nifedipine: dependence on left ventricular function. Circulation 1982; 65: 489-98.

10 Elkayam U, Weber L, Rose J, McKay C, Rahimtoola S. Nifedipine versus hydralazine in the treatment of severe heart failure: an evidence for a negative inotropic effect of nifedipine [Abstract]. Circulation 1983; 68 (Part II): III-8.

11 Brooks N, Cattell M, Pidgeon J, Balcon R. Unpredictable response to nifedipine in severe heart failure. $\mathrm{Br}$ Med f 1980; 281 : 1324.

12 Anastassiades CJ. Nifedipine and beta blocker drugs. $\mathrm{Br}$ Med F 1980; 281: 1251-2.

13 Robson RH, Vishwanath MC. Nifedipine and betablockade as a cause of cardiac failure. $\mathrm{Br}$ Med $\mathcal{F}$ 1982; 284: 104. 
14 Gillmer DJ, Kark P. Pulmonary oedema precipitated by nifedipine. Br Med f 1980; 280: 1420-1.

15 Ljung B. Vascular versus myocardial selectivity in vitro

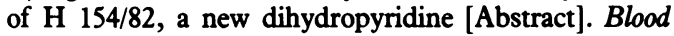
Vessels 1980; 17 : 154.

16 Boström S-L, Ljung B, Mårdh S, Forsen S, Thulin E. Interaction of the antihypertensive drug felodipine with calmodulin. Nature 1981; 292: 777-8.

17 Ganz W, Tamura K, Marcus HS, Donoso R, Yoshida S, Swan HJC. Measurement of coronary sinus blood flow by continuous thermodilution in man. Circulation 1971; 44: 181-95.

18 Lauwerys RR. Colorimetric determination of free fatty acids. Anal Biochem 1969; 32: 331-3.

19 Livesley B, Atkinson L. Accurate quantitative estimation of lactate in whole blood [Letter]. Clin Chem 1974; 20: $1478-81$.

20 Mager M, Farese G. What is "true" blood glucose? A comparison of three procedures. Am F Clin Pathol 1965; 44: 104-8.

21 Wallenstein S, Zucker CL, Fleiss JL. Some statistical methods useful in circulation research. Circ Res 1980; 47: 1-9.

22 Smith TW, Braunwald E. The management of heart failure. In: Braunwald E, ed. Heart disease. Philadelphia: WB Saunders, 1980: 509-70.

23 Borow KM, Neumann A, Wynne J. Sensitivity of endsystolic pressure-dimension and pressure-volume rela- tions to the inotropic state in humans. Circulation 1982; 65: 988-97.

24 Suga H, Sagawa K. Assessment of absolute volume from diameter of the intact canine left ventricular cavity. $\mathcal{F}$ Appl Physiol 1974; 36: 496-9.

25 Sagawa K. The ventricular pressure-volume diagram revisited. Circ Res 1978; 43: 677-87.

26 Wallace AG, Skinner NS Jr, Mitchell JH. Hemodynamic determinants of maximal rate of rise of left ventricular pressure. Am J Physiol 1963; 205: 30-6.

27 Mason DT, Braunwald E, Covell JW, Sonnenblick EH, Ross J Jr. Assessment of cardiac contractility. The relation between the rate of pressure rise and ventricular pressure during isovolumic systole. Circulation 1971; 44: 47-58.

28 Gray R, Chatterjee K, Vyden JK, Ganz W, Forrester JS, Swan HJC. Hemodynamic and metabolic effects of isosorbide dinitrate in chronic congestive heart failure. Am Heart f 1975; 90: 346-52.

29 Braunwald E. Control of myocardial oxygen consumption. Physiologic and clinical considerations. Am $\mathcal{F}$ Cardiol 1971; 27: 416-32.

30 Rubio R, Berne RM. Regulation of coronary blood flow. Prog Cardiovasc Dis 1975; 18: 105-22.

31 Pierpont G, Hale KA, Franciosa JA, Cohn JN. Effects of vasodilators on pulmonary hemodynamics and gas exchange in left ventricular failure. Am Heart $\mathcal{F}$ 1980; 99: 208-16. 